\title{
Spectroscopic Examinations, Antimicrobial and Anti-corrosive Evaluations of Polyurethanes Synthesized from Thevetia Peruviana Seed Oil
}

\author{
T. O. SIYANBOLA ${ }^{1 *}$, A. F. AKINSOLA ${ }^{2}$, J.A. ADEKOYA ${ }^{1}$, \\ K.O. OGUNNIRAN ${ }^{1}$, O.A. JOKOTAGBA ${ }^{3}$, A. EDOBOR-OSOH$^{1}$, \\ C. O. AKINTAYO ${ }^{4}$, O. OLAOFE ${ }^{2}$ and E.T. AKINTAYO ${ }^{2}$
}

${ }^{1}$ Department of Chemistry, Covenant University, P.M.B. 1023, Ota, Ogun State, Nigeria.
${ }^{2}$ Department of Chemistry, Ekiti State University, P.M.B. 5363, Ado-Ekiti, Nigeria.
${ }^{3}$ Department of Science Laboratory Technology, Abraham Adesanya
Polytechnic, P.M.B. 1020, ljebu-Igbo, Ogun State, Nigeria.
${ }^{4}$ Chemistry Department, Federal University Oye Ekiti, Ekiti State, Nigeria.
${ }^{*}$ Corresponding author E-mail: tolu.siyanbola@ @ovenantuniversity.edu.ng

http://dx.doi.org/10.13005/ojc/320139

(Received: November 23, 2015; Accepted: March 16, 2016)

\begin{abstract}
Seed oil based polyurethane resins were synthesized from underutilized plant seedlings of Thevetia peruviana (yellow oleanda). The seed oil was converted to partial glycerides (PG) polyol using calcium oxide as catalyst. The polyol was treated with varying ratios of isophorone diisocyanate (IPDI) in order to synthesize partial glyceride urethanes (PGU) films. The PG intermediate and PGU products were characterized using FT-IR, ${ }^{1} \mathrm{H}-\mathrm{NMR}$ and ${ }^{13} \mathrm{C}-\mathrm{NMR}$. Physico-chemical parameters like acid value, hydroxyl value, viscosity and refractive index were also examined. Corrosion stability of coated panels was studied in the salt spray chamber. Thermal stability and antimicrobial study of the films were also evaluated.
\end{abstract}

Key words: Partial Glycerides, Polyurethane, Corrosion, Antimicrobial, Seed Oil.

\section{INTRODUCTION}

The absolute dependency of the world on crude oil as its primary source of energy and industrial feed stock as continue to create global market and environmental crises of today. The degradation of the world polity and regional wars are not left out, because their underlying reasons and interest are centered on this limited and non-ecofriendly based material (petroleum) ${ }^{1-3}$. Sustainable resource materials like cellulose and starch, proteins, natural rubber and vegetable seed oils are capable of providing eco-friendly chemicals and polymeric based feeds as substitute to petroleum feed stocks ${ }^{4}$. The development of polymeric based materials (polyols and urethanes) from sustainable 
resources to useful industrial products cannot be overemphasized, studies has shown that medical devices, adhesives, footwear, elastomers, wall foam insulation, bone regeneration, biodiesel, lubricants, automotive interiors and their coats can be synthesized vegetable seed oils ${ }^{4-7}$. Vegetable seed oils of castor, linseed, nahar, soybean, Annona squamosal, Pongamia glabra and others have been used in the synthesis of polyesteramides ${ }^{1}$, polyetheramides $^{8}$, alkyds, epoxides ${ }^{9}$, polyurethanes ${ }^{10}$ and other polymeric resins. However, there are some underutilized seed oils whose potentials in coating system formulations have not been adequately represented despite their rich percentage yield. Example of such underutilized seed oil is that gotten from Thevetia peruviana plant popularly known as yellow oleanda, lucky nut, milk bush or "olomi ojo" in
Yoruba Southwestern Nigeria having about $63 \%$ oil yield ${ }^{1}$. Thevetia peruviana is a 7 meters tall ornamental shrub native to Central and South America,belonging to the order Apocynales and Apocynaceae family ${ }^{11,12}$. The fact that Thevetia peruviana seed oil (TPSO) is a non-drying one and does not possess functional groups such as hydroxyl or epoxide that can react with neither isocyanate nor ring opening performed on the oxirane ring it will require modifications such aminolysis, hydroformulation, epoxidation, transesterification or partial glyceride formation ${ }^{10}$. Partial glyceride (PG) polyol formation is a vital synthetic step towards the preparation of functional organic resins. In this respect, few partial glyceride based monomeric polyols have been synthesized from drying and semidrying seed oils ${ }^{10,13}$. The partial glyceride polyolsprepared from Thevetia peruviana

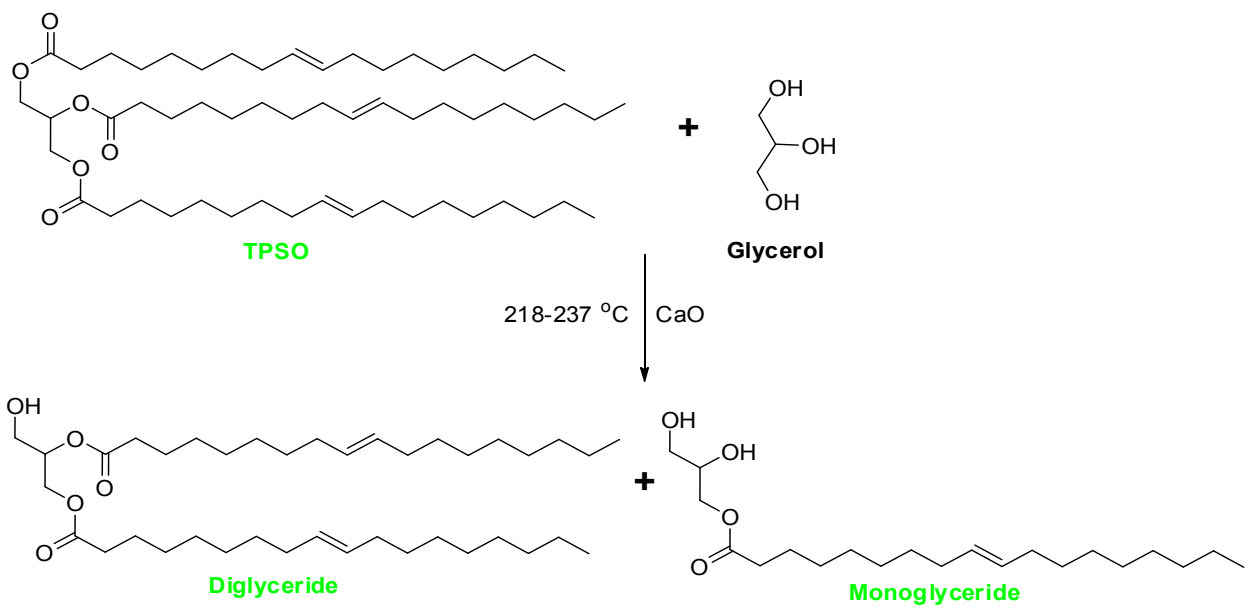

Scheme. 1: Synthesis of polyols (Monoglyceride and Diglyceride)

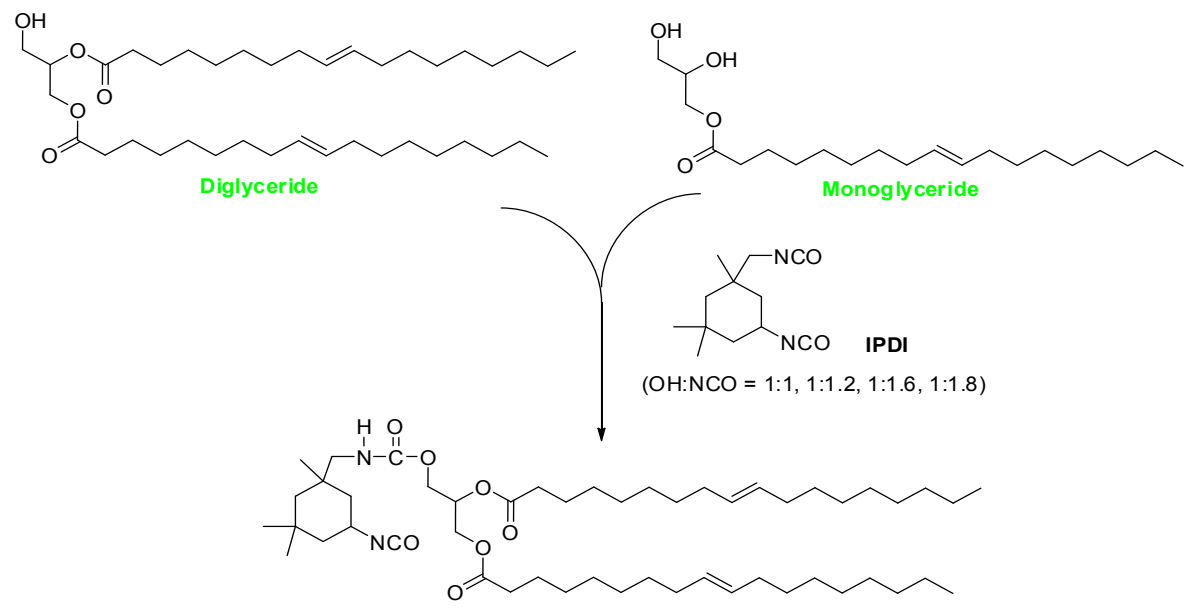

Scheme 2: Synthesis of partial glyceride urethanes (PGU) 
seed oil possessing $69.1 \%$ unsaturated and $30.1 \%$ saturated fatty acids was made to react with varying ratios of isophorone diisocyanate (IPDI). The seed oil, partial glycerides and urethanes synthesized from this process were characterized by FT-IR, ${ }^{1} \mathrm{H}$ NMR and ${ }^{13} \mathrm{C}$ NMR. The physicochemical properties, chemical resistance and antibacterial test of the coating were carried out.

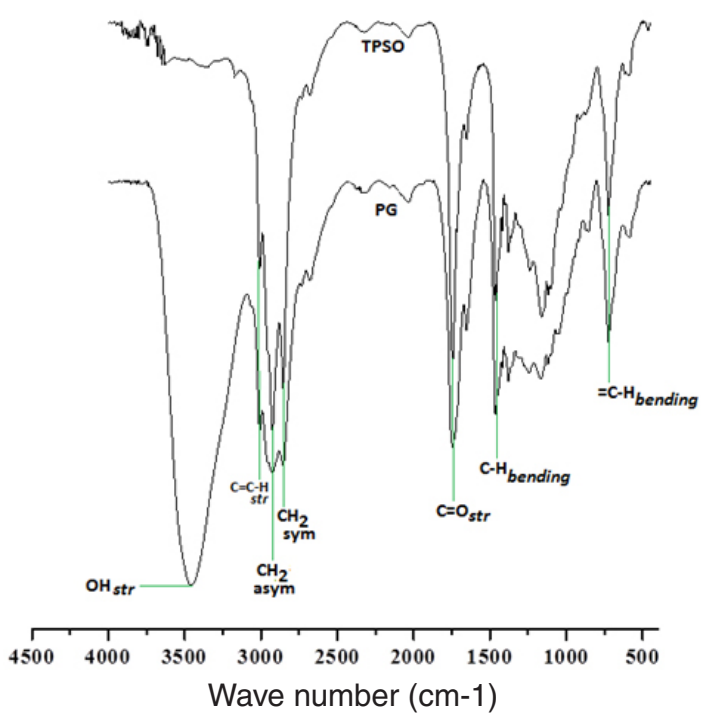

Fig. 1: Overlay FTIR spectral of TPSO and PG

\section{MATERIALS}

Soxhlet apparatus(with $n$-hexane as solvent) was used to extract seed oil from air-dried Thevetia peruviana seedlings obtained from the compound of Alhaji and Alhaja R.A. Amodu at Emure-Ekiti, south-western Nigeria. Calcium oxide, potassium hydroxide, carbon tetrachloride, iodine trichloride and glycerol were obtained from S.D. Fine Chemicals (Mumbai, India). Isophorone diisocyanate (IPDI) was procured from Alfa Aesar Chemicals UK.The fattyacid composition of the oil was carried out using a gaschromatography (GC; HP-1 ms, 30 $\mathrm{m} \times 0.25 \mathrm{~mm} \times 0.25 \mathrm{ìm}$, FID detector).

\section{METHODS}

The chemical structure of TPSO, partial glyceride polyol (PG) and its urethanes were characterized by FTIR, ${ }^{1} \mathrm{H}-\mathrm{NMR}$ and ${ }^{13} \mathrm{C}$-NMR. FTIR spectra of the resin were taken over $\mathrm{KBr}$ on Perkin Elmer spectrum 100 spectrometer (PerkinElmer Inc. USA) by scanning 8 times. ${ }^{1} \mathrm{H}-\mathrm{NMR}$ and ${ }^{13} \mathrm{C}-\mathrm{NMR}$ were respectively recorded on Varian VXR-Unity $200 \mathrm{MHZ}$ spectrometer and Bruker UXNMR 400 $\mathrm{MHZ}$ spectrometer by using $\mathrm{CDCl}_{3}$ and DMSO$d_{6}$ as a solvent and teramethylsilane (TMS) as an internal standard. The thermal stability of the

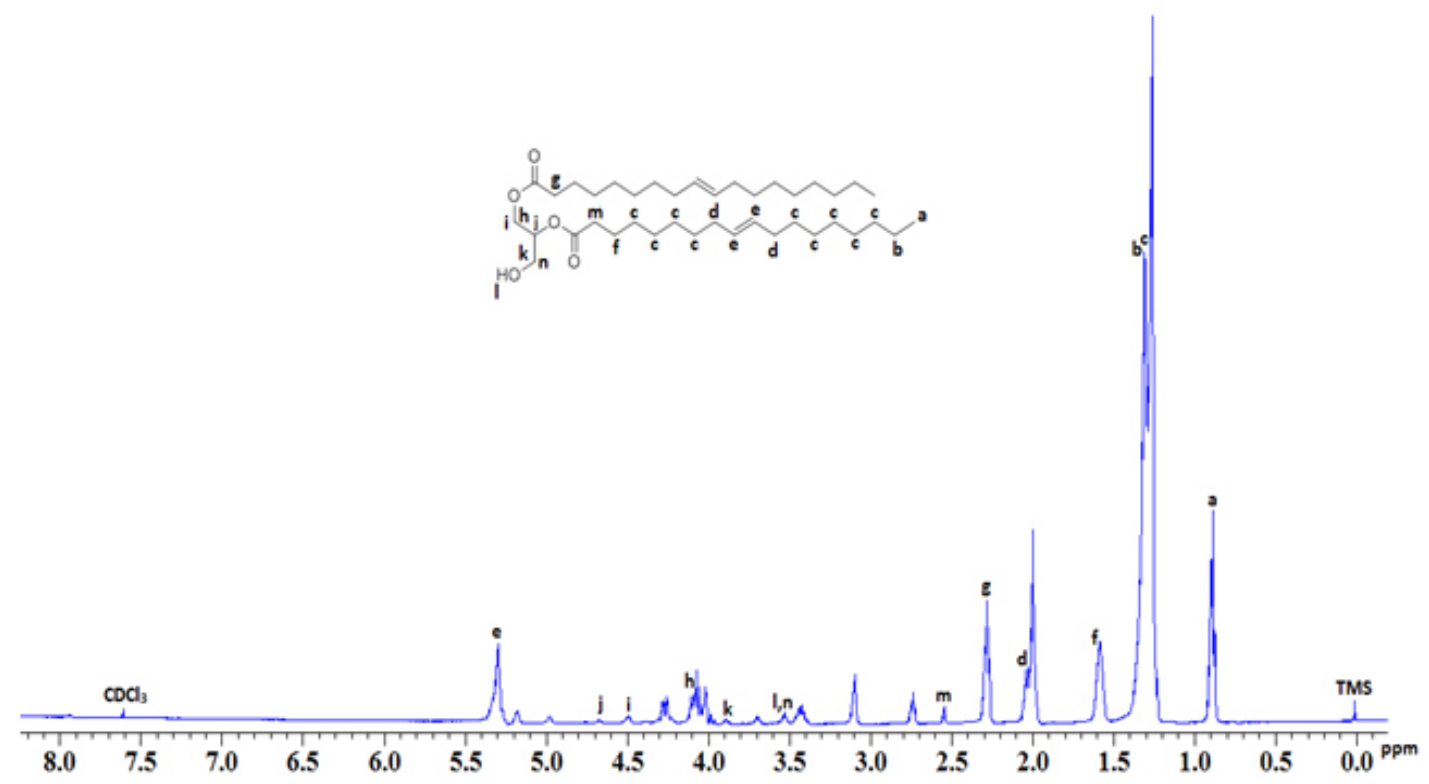

Fig. 2: 1H-NMR spectral of PG polyol 
hybrid resins and curing behaviour were studied by thermogravimetric analysis (Perkin Elmer TGA 7, TA Instrument, and USA) at a constant heating rate of $10^{\circ} \mathrm{C}$ min 1 in nitrogen atmosphere. Elcometer was used in taking the thickness of the coatings on metal steel panels.A refractometer RFM 800 instrument was used to analyze the refractive indices of all the resin samples. The acid and hydroxyl values of the resin samples were determined by using the ASTM D1639-89 and ASTM D4274-94 procedures ${ }^{10}$.

In vitro antimicrobial activity of the polymers was studied and tested against Grampositive organisms viz. Bacillus subtilis (MTCC 441), Staphylococcus aureus (MTCC 96) and Gramnegative organisms viz Escherichia coli (MTCC

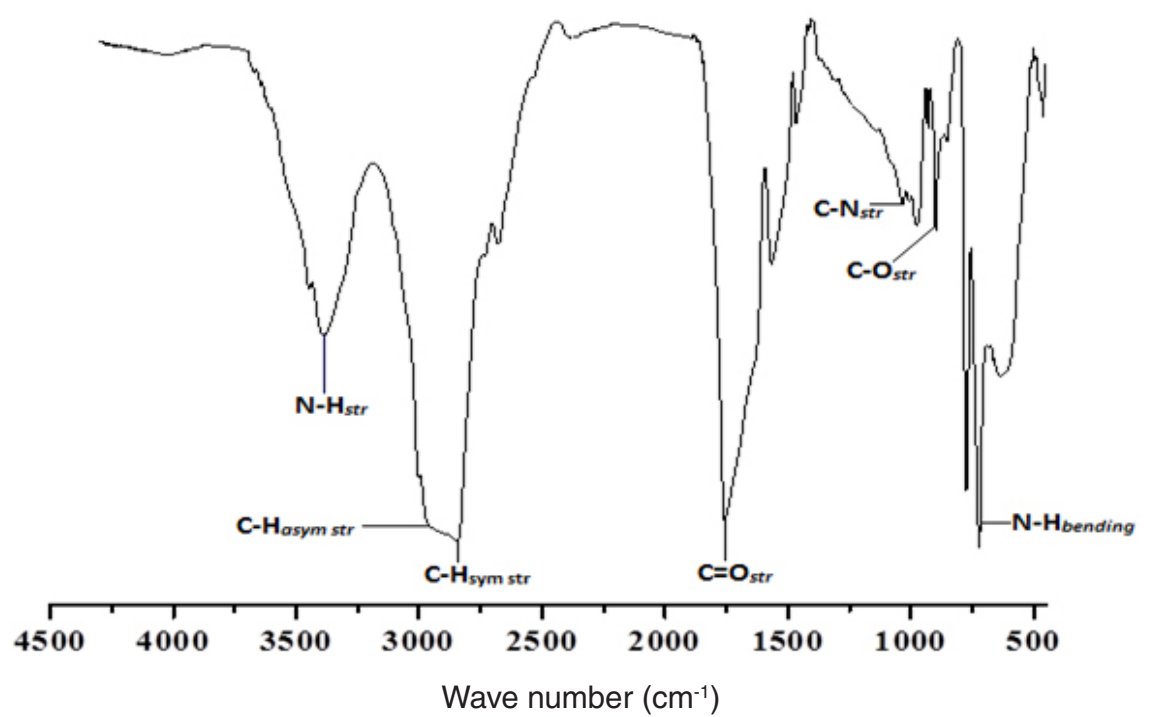

Fig. 3: FTIR spectrum of PGU
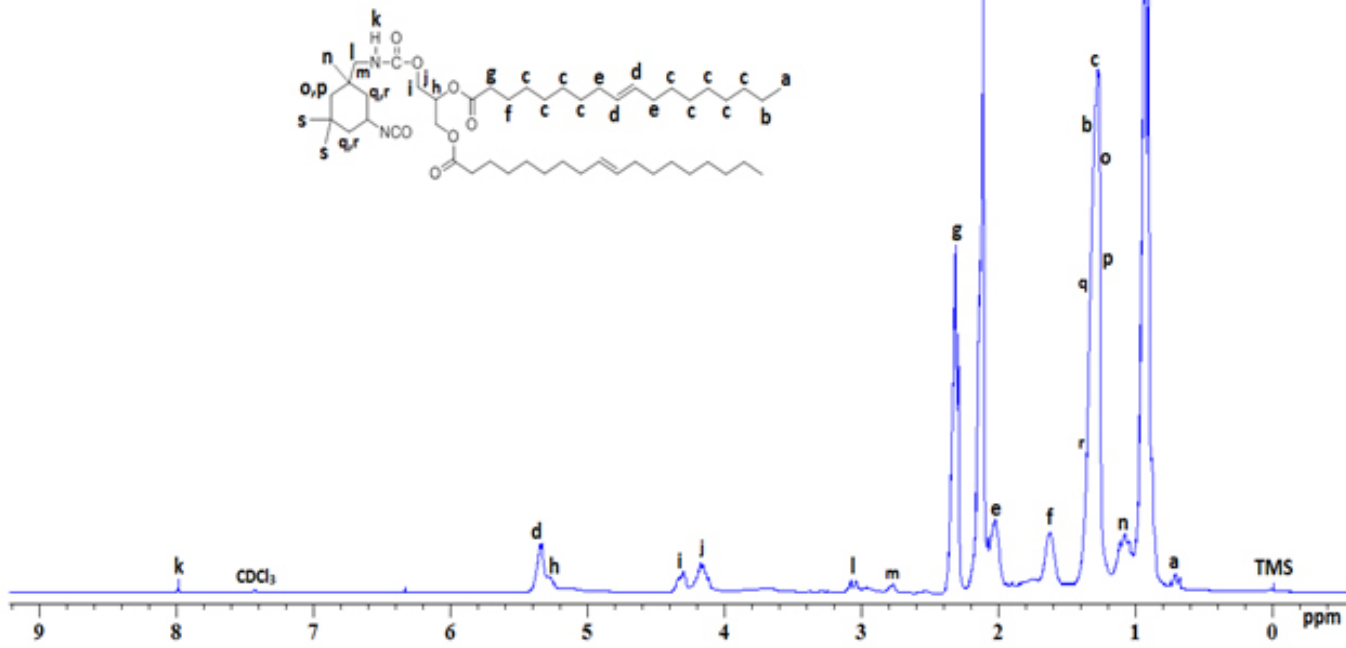

Fig. 4: 1H-NMR spectral of PGU 
443), and klebsiella pneumoniae (MTCC 618) by Agar diffusion Method $^{15}$. The ready-made nutrient Agar was suspended in distilled water $(1000 \mathrm{~mL})$ and heated to boiling until it dissolved completely; the medium and Petri dishes were autoclaved at pressure of $15 \mathrm{lb} / \mathrm{inc} 2$ for $20 \mathrm{~min}$. The medium was poured into sterile Petri dishes under aseptic conditions in a laminar air flow chamber. When the medium in the plates solidified, $0.5 \mathrm{~mL}$ (approx. 106 $\mathrm{CFU} / \mathrm{mL}$ ) of culture of test organism was inoculated and uniformly spread over the agar surface with a sterile L-shaped rod. Embedded polymer samples with $2 \times 2 \mathrm{~cm}$ (approx) samples were washed with double distilled water and placed on the medium and incubated at $37^{\circ} \mathrm{C}$ (bacteria) for 24 hours. Uncoated polymers were used as Controls. The antibacterial activity was performed based on the formation of inhibition zone loss of growth of organism beneath and surroundings of the films placed on agar medium. Three replicates were maintained for each treatment. MTCC is the Microbial Type Culture Collection in IMTECH (CSIR LAB) Chandigarh, India ${ }^{10,14}$.

Different grades of Silicon carbide papers were used for the preparation of mild steel strips; which were washed with water, ethanol and acetone. The degreased metal strips were dried under a vacuum for 3 hours. The pristine and hybrid coatings were prepared by brush application of $60 \mathrm{wt} \%$ resin in xylene on the mild steel strips. Forthe chemical resistance test in water, acid $(5 \mathrm{wt} \% \mathrm{HCl})$, alkali (5 wt $\% \mathrm{NaOH}$ ) standard sizes of mild steel strips of $30 \mathrm{~mm} \times 10 \mathrm{~mm} \times 1 \mathrm{~mm}$ were placed in $3 \mathrm{in}$. diameter porcelain dishes. The salt spray tests were conducted in a salt mist chamber following ASTM B $117-11^{10}$.

\section{Synthesis of partial glycerides polyols from Thevetia peruviana seed oil}

The partial glyceride polyol (PG) was synthesized in a four-necked round bottom flask fitted with thermometer, mechanical stirrer, condenser and a nitrogen inlet tube. The reaction system containing $100 \mathrm{~g}$ of TPSO and $8.5 \mathrm{~g}$ of glycerol was heated to 218 C. On getting to this temperature, $0.01 \mathrm{~g}$ of calcium oxide was added as catalyst. The temperature was raised to $232-237^{\circ} \mathrm{C}$ and maintained for 45 minutes (Scheme 1). The progress of the reaction as well as the polyol product was monitored by acid and hydroxyl values determination ${ }^{10,16}$.

\section{Synthesis of partial glyceride urethanes (PGU)}

$8.72 \mathrm{~g}$ of $P G$ polyol were dissolved in 4-methyl pentan-2-one in a three-necked roundbottom flask and made to react with calculated ratios $(1: 1,1: 1.2,1: 1.6$ and $1: 1.8$ with respect to $\mathrm{PG}$ ) of Isophorone diisocyanate at $75^{\circ} \mathrm{C}$ for 3 hours under a nitrogen atmosphere and stirring condition

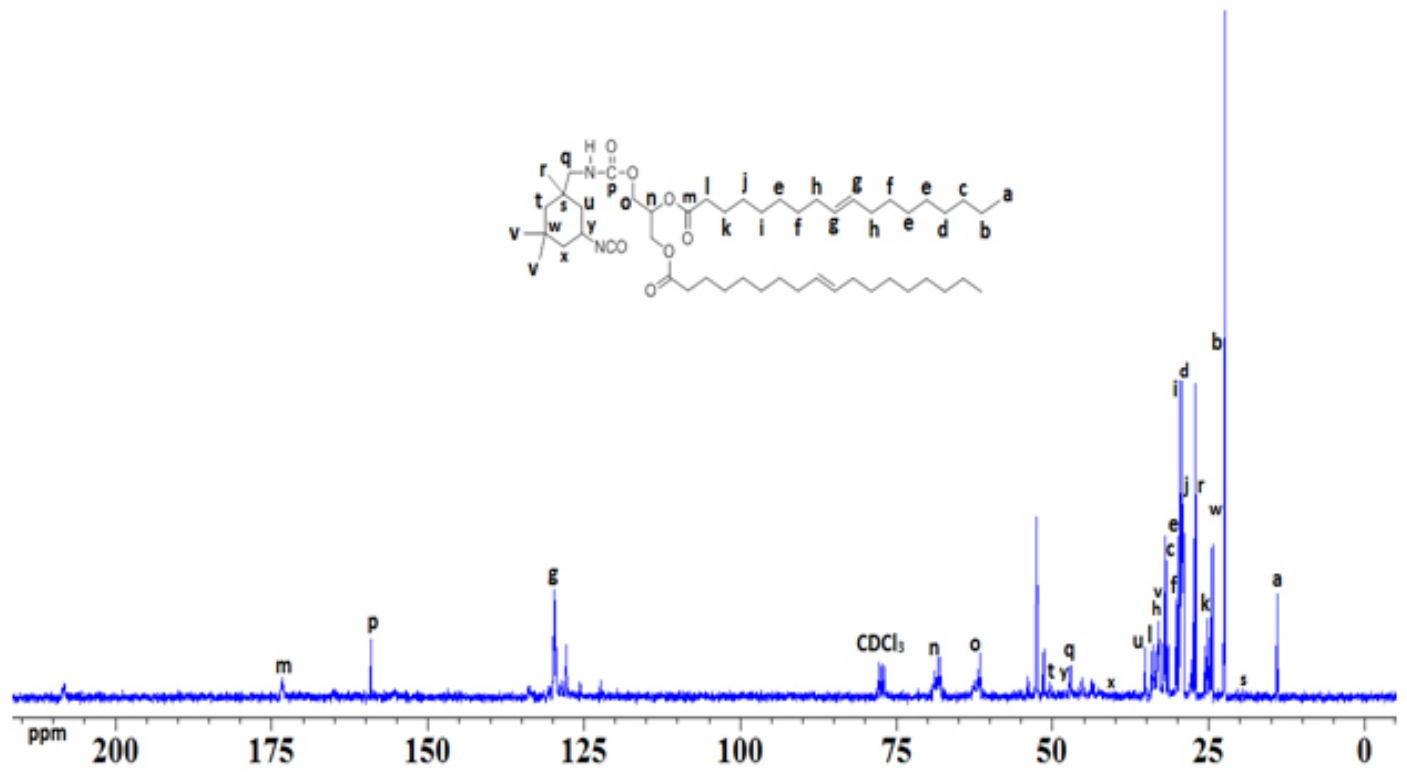

Fig. 5: 13C-NMR spectral of PGU 
(Scheme 2). The progress of the reaction was monitored by TLC and hydroxyl value determination. Urethane solutions from various ratios were ratios were manually casted on tin foil (supported over a glass plate using driven square shaped applicator) and on mild steel panels. They were both cured under atmospheric moisture at ambient temperature for 1 week. The cured urethanes were thereafter evaluated. Cured coating films were coded as PGU, PGU1.2, PGU1.6 and PGU1.8.

\section{RESULTS AND DISCUSSIONS}

Table 1 present the physico-chemical characterization data for TPSO, PG (polyol) and PGU (urethane resin). The acid and hydroxyl values of TPSO under this investigation (i.e. $2.7 \mathrm{mg} \mathrm{KOH} / \mathrm{g}$, $75.6 \mathrm{gl}_{2} / 100 \mathrm{~g}$ respectively) is slightly higher than that reported by Siyanbola et al. 2013 and Siyanbola et al. 2015 despite the fact that both samples where obtained from the same environment. These slight differences of values could be attributed to the different sampling season of Thevetia peruviana seedlings ${ }^{1,10}$. The respective decrease in iodine and hydroxyl values from TPSO to PG 1.8 and TPSO to $P G U$ in Table 1, and increase in the refractive index of the said samples can be correlated to the molar mass increase of the resulting products (i.e. polyol formation and subsequently increase in urethane linkages). The solubility attribute of PG, PGU 1.2 and PGU 1.6 were studied in the following solvents; DMSO, chloroform, ethanol, methanol, DMF, acetone, xylene, MIBK, toluene and diethyl ether (testing was carried out by taking 0.1-0.2 g resin sample in $10 \mathrm{ml}$ of solvent and stirring well for up to 15 minutes and slightly heating if necessary $)^{10}$. About
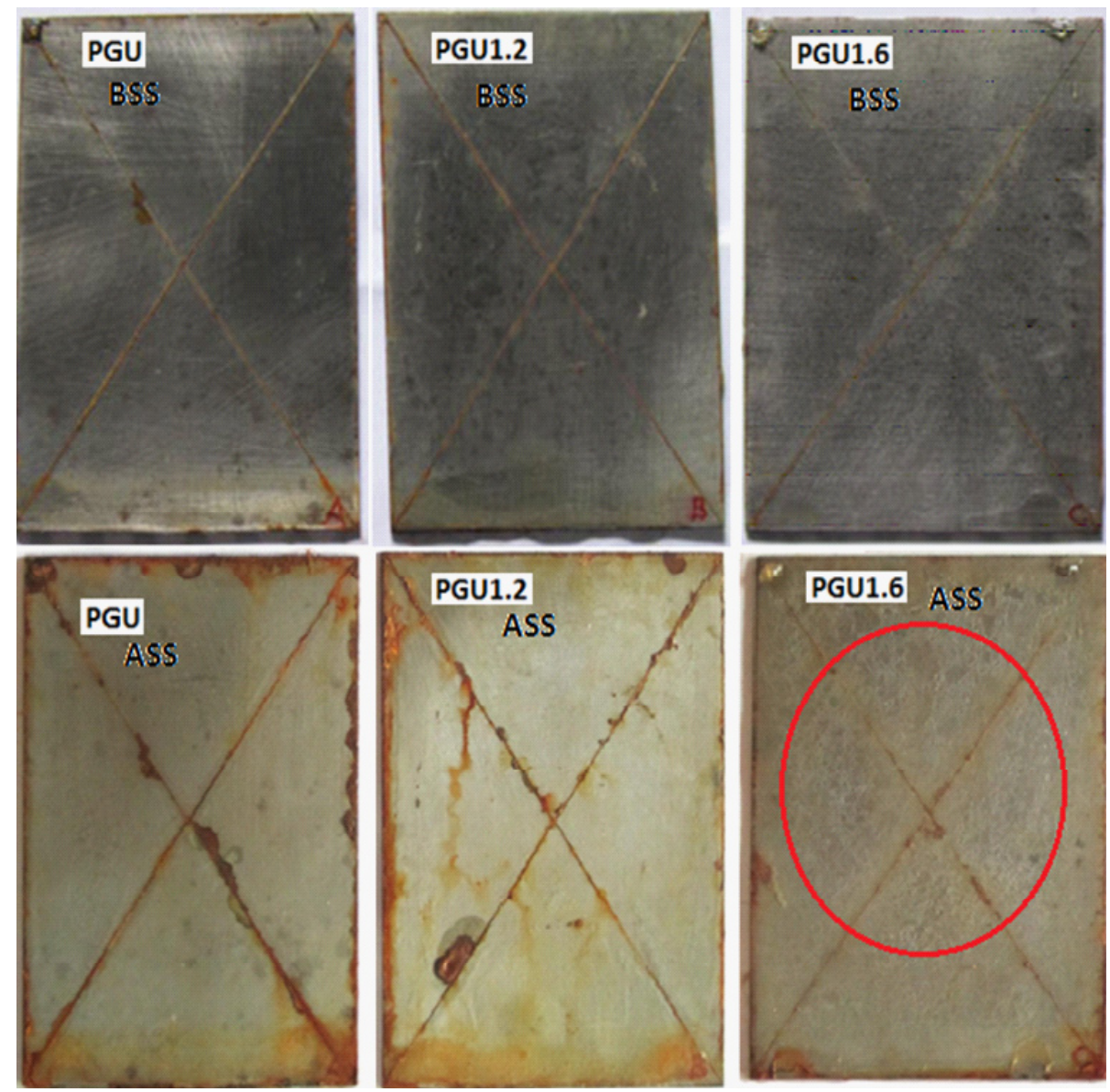

Fig. 6: Panel salt spray results of 380 hours of $5 \%$ NaCl solution spray (Here BSS and ASS represent Before Salt Spray and After Salt Spray respectively) 
$97 \%$ solubility was observed from samples in studied solvents, all having slight transparent light yellow colouration however, and sparingly solubility were seen in polar solvents (methanol and ethanol).

\section{FTIR and NMR spectral analysis}

The overlaid FTIR spectral of TPSO and $P G$ in Figure 1 shows characteristic broad band absorption at $3456 \mathrm{~cm}^{-1}$ on the $P G$ spectrum, which corresponds to the alcoholic -OH functional group. This $-\mathrm{OH}$ peak hump confirms the formation of $P G$ polyol. The ester carbonyl stretching vibrations at $1747 \mathrm{~cm}^{-1}$ and $1741 \mathrm{~cm}^{-1}$ are the respective representation of bands on TPSO and PG. Asymmetric and symmetric $-\mathrm{CH}_{2}$ for TPSO and PG are observed at $2943 \mathrm{~cm}^{-1}, 2861 \mathrm{~cm}^{-1}$ and $2932 \mathrm{~cm}^{-1}$, $2872 \mathrm{~cm}^{-1}$ respectively. The alkane $\mathrm{C}-\mathrm{H}$ scissoring and bending vibration for TPSO and PG absorptions are at $1466 \mathrm{~cm}^{-1}$ and $1463 \mathrm{~cm}^{-1}$ respectively. The PG polyol structure is further confirmed by the ${ }^{1} \mathrm{H}-\mathrm{NMR}$ studies in Figure 2. The chemical shift attributed to the terminal methyl protons of the fatty acids are observed at 0.86-0.90 ppm. The double bond protons on the fatty acid chains are seen at $35.32 \mathrm{ppm}$ while the internal methylene protons resonated at ä 1.29 ppm. The hydroxyl proton on the PG is observed at $\ddot{a}=3.52 \mathrm{ppm}$. The respective chemical shifts at 4.49 ppm: 4.09 ppm, 3.82 ppm: 3.52 ppm and 4.66 ppm represent the $-\mathrm{CH}_{2}$ and $-\mathrm{CH}$ back bone of glycerol.

Partial glyceride urethane (PGU) FTIR spectrum is presented in Figure 3 . The presence of $\mathrm{N}-\mathrm{H}$ characteristic stretching peak at $3341 \mathrm{~cm}^{-1}$ confirms the formation of polyurethane linkage.

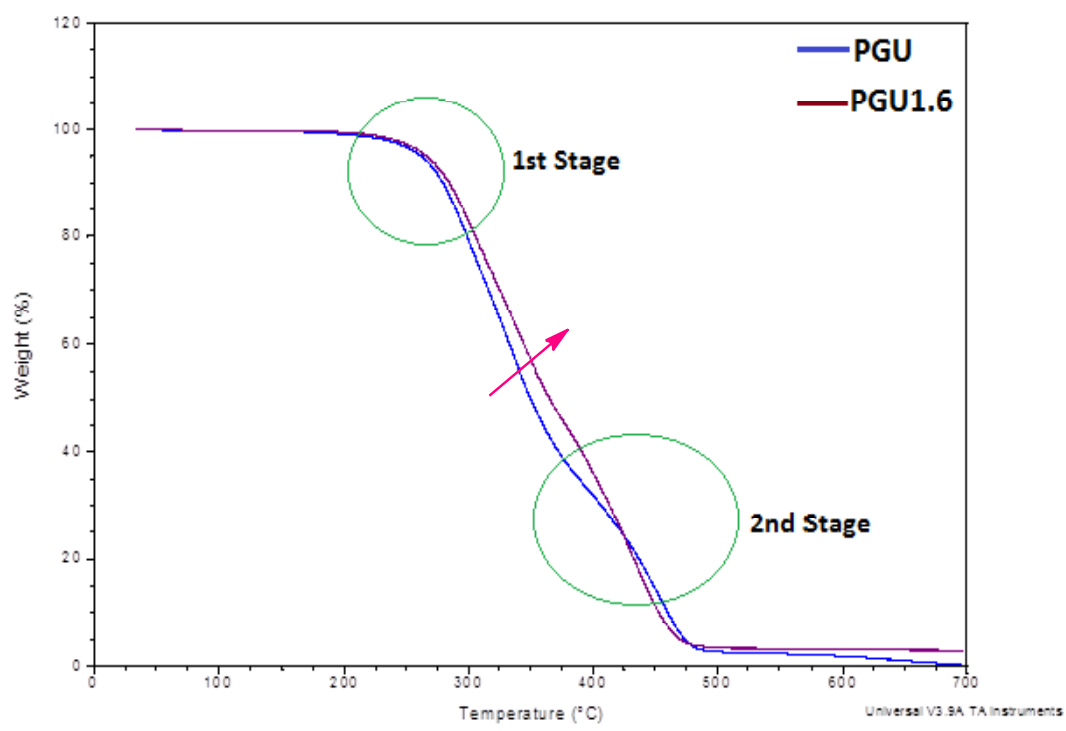

Fig. 7

Table 1: Physico-chemical characterizations of TPSO and Resins

\begin{tabular}{|c|c|c|c|c|c|}
\hline \multicolumn{3}{|c|}{$\begin{array}{l}\text { Sample/Resin Acid valuelodine value } \\
(\mathrm{mg} \mathrm{KOH} / \mathrm{g})(\mathrm{gl} / 2 / 100 \mathrm{~g})\end{array}$} & \multirow{2}{*}{$\begin{array}{c}\text { Hydroxyl } \\
\text { value (\%) } \\
0\end{array}$} & \multirow{2}{*}{$\begin{array}{c}\text { Viscosity } \\
\text { [(cSt) at } \\
\left.40^{\circ} \mathrm{C}\right] \\
35.8\end{array}$} & \multirow{2}{*}{$\begin{array}{c}\begin{array}{r}\text { Refractive } \\
\text { index } 40^{\circ} \mathbf{C}\end{array} \\
1.4931\end{array}$} \\
\hline TPSO & 2.7 & 75.6 & & & \\
\hline$P G$ & 5.92 & 37.9 & 33.51 & 986.31 & 1.5729 \\
\hline PGU & ND & 11.7 & 5.62 & ND & 1.6365 \\
\hline PGU 1.2 & ND & 11.2 & 0 & ND & 1.6972 \\
\hline PGU 1.6 & ND & 10.6 & 0 & ND & 1.7624 \\
\hline PGU 1.8 & ND & 9.4 & 0 & ND & ND \\
\hline
\end{tabular}


Absorption peaks around 2908 and $2846 \mathrm{~cm}^{-1}$ corresponds to $\mathrm{C}-\mathrm{H}$ asymmetric and symmetric stretching vibrations. A medium weak $\mathrm{C}-\mathrm{N}$ stretching vibration of urethane linkage is observed at $1238 \mathrm{~cm}^{-1}$ while the absorption hump at $1748 \mathrm{~cm}^{-1}$ corresponds to ester and urethane $\mathrm{C}=\mathrm{O}$ stretching vibration. The spectral from ${ }^{1} \mathrm{H}$-NMR and ${ }^{13} \mathrm{C}-\mathrm{NMR}$ analysis further confirm the formation of the synthesized polyurethanes. The ${ }^{1} \mathrm{H}-\mathrm{NMR}$ spectrum in Figure 4 reveals the presence of urethane $\mathrm{N}-\mathrm{H}$ at ä $8.01 \mathrm{ppm}$ and the presence of IPDI cyclohexane ring protons resonates within ä 1.20-3.14 ppm. The methylene protons attached to oxygen linking the urethane functional group (- $\left.\mathrm{CH}_{2}-\mathrm{O}-\mathrm{CO}-\mathrm{NH}-\right)$ resonates at 4.18 ppm and $4.32 \mathrm{ppm}$ is significant towards confirming the formation of the polyurethane. However, the fatty acid methylene protons is seen at $1.28 \mathrm{ppm}$ while the terminal methyl $\left(-\mathrm{CH}_{3}\right)$ protons of the fatty acidchain was observed at ä $1.20 \mathrm{ppm}$. The ${ }^{13} \mathrm{C}$ NMR spectroscopy in Figure 5 presents the urethane carbonyl (-NHCO-) peak at ä 159.2 ppm and IPDI cyclohexane cum peaks of the internal methylene carbon $\left(-\mathrm{CH}_{2}-\right)$ of fatty acid chains range from 18.6-49.5 ppm. However, the terminal methyl carbon resonates at ä 13.9 ppm. The double bond carbons $(-\mathbf{C}=\mathbf{C}-)$ and the carbonyl carbon $(-\mathbf{C}=0)$ on the fatty acid chain respectively appeared at 129.9 ppm and $173.2 \mathrm{ppm}$.

\section{Fog Test}

Three panels with dimension $3 \times 4 \mathrm{~cm}$ where coated with PGU, PGU1.2 and PGU1.6 with thickness around 100 microns in order to evaluate the anticorrosion properties in $5 \% \mathrm{NaCl}$ salt fog chamber. The coatings were cast on the panels on addition of dibutyl tin dilaurate catalyst to urethane solutions. The urethane films on the panels became dried to touch in about 50 minutes after they were casted but became tack free in 7 hours. These developments is as a result of chain entanglement in the coating systems and afterwards produce an environment whereby free unreacted isocyanate groups chemically react with moisture forming urea linkages or the already formed urethane group, thereby leading to the formation of allophanate ${ }^{14}$, ${ }^{17}$.Figure 6 shows the photographic representation of coated panels before and after 380 hours of salt spray. From the photographic image of the panels it clearly shows that edge and cross sectional cut corrosion was most observed on PGU panel followed by PGU1.2. PGU1.6 showed the list corrosion effect; this observation may be due to 1.6 percentage composition of IPDI in the system (hence, possessing high cross-linking density of the urethane matrix). However, PGU1.6 shows somewhat blistering effects on its panel (as indicated with red circle), which may also be as a result of its IPDI percentage composition.

\section{Thermal Analysis of films}

Thermogravimetric (TGA) analysis of PGU and PGU1.6 are presented in Figure 7. The first stage on the thermogram corresponds to degradations of soft ester bond linkages while the second stage corresponds to urethane and urea groups. This degradation step may be as a result of dissociation of isocyanate and alcohol leading to primary and secondary amines cum olefins formation. The second stage degradation is not as prominent as the first stage. From the TGA thermogram, thermal stability is seen to increase as the percentage composition of isocyanate increases ${ }^{1,18}$.

\section{Antimicrobial Examinations}

The inhibitive tendencies of PGU, PGU1.2 and PGU1.6 films were studied on common gram

Table 2: Antimicrobial activities of PGU, PGU1.2 and PGU1.6

\begin{tabular}{lccccc} 
Sample Staphylococcus & Bacillus \\
aureus & subtilis & $\begin{array}{c}\text { Escherichia } \\
\text { coli }\end{array}$ & $\begin{array}{c}\text { Klebsiella } \\
\text { pneumonia }\end{array}$ & $\begin{array}{c}\text { Aspergillus } \\
\text { niger }\end{array}$ \\
\hline PGU & + & - & + & - & - \\
PGU1.2 & + & N.D & + & + & + \\
PGU1.6 & ++ & - & + & + & ++ \\
\hline
\end{tabular}

“+” represents samples antimicrobial activity, "-” represents samples inactivity and N.D implies Not Determined 
positive and gram negative bacterial strains as well as fungi stains, which were all grown on a CzapekDox medium. In these grown stains, the coating films were embedded and incubated for 24 hour at an ambient temperature of $28 \pm 4{ }^{\circ} \mathrm{C}$. The antimicrobial activities were determined based on the formation of an inhibition zone on the bacterial or fungal growth beneath and in the surroundings of the films that was placed on the Luria-Bertani agar medium ${ }^{10}$. All the antimicrobial test results are given in Table 2 . The inhibitive activity of the PGU1.2 and PGU1.6 films seems to be better than PGU because they both have activities on Klebsiella pneumonia and Aspergillus niger. However, sample films tested all show nil activity for Bacillus subtilis.

\section{CONCLUSION}

This study provides base template towards formulations that will involve incorporation of materials within the polymeric matrix of the studied films. From the study, the brittle nature of PGU1.6 film will not present its polymeric matrix for effective hybrid modifications such as incorporation of nanomaterials for other uses. Rather, PGU1.2 will be preferred because of its percentage composition of isocyanate hence, less brittle. Thermal stability as well as antimicrobial activities was enhanced by increase in percentage composition of isocyanate in the systems. PGU1.8 film was not examined for TGA, anticorrosive and antimicrobial evaluations because of the brittle nature of the film.

\section{ACKNOWLEDGEMENTS}

The author Dr. Tolutope O. Siyanbola appreciates CSIR-TWAS for the 2010 Sandwich Postgraduate Fellowship Award (FR number: 3240240268). I am thankful to my host Dr. KVSN Raju of IICT, Hyderabad, India for the efficient guidance giving me during my study in India. Dr. Oladele O. James of Kwara State University, Nigeria is well appreciated for his mentorship.

\section{REFERENCES}

1. Siyanbola, T. O.; Sasidhar, K.; Anjaneyulu, B.; Kumar, K. P.; Rao, B. V. S. K.; Narayan, R.; Olaofe, O.; Akintayo, E. T.; Raju, K. V. S. N. J. Mater. Sci.2013,48, 8215-8227.

2. Siyanbola, T. O.; Ajanaku, K. O.; James, O. O.; Olugbuyiro, J. A. O.; Adekoya, J. A.G. J. P. and A. Sci. and Tech.2011, 1, 49-54.

3. Baumann, H.; Buhler, M.; Fochem, H.; Hirsinger, F.; Zoebelein, H.; Falbe, J.Angew Chem. In. Ed.2003,27, 41.

4. Lu, Y.; Larock, R. C. ChemSusChem. 2009,2, 136-147.

5. Pfister, D. P.; Xia, Y.; Larock, R. C.ChemSumChem.2011,4, 703-717.

6. Lligadas, G.; Ronda, J. C.; Galià, M.; Cá diz, V. Biomacromolecules.2010, 11, 2825-2835.

7. Shaik, A.; Narayan, R.; Raju, K. V.S. N. J. Coat. Technol. Res.2014, DOI 10.1007/s11998013-9548-5.

8. Alam, M.; Sharmin, E.; Ashraf, S. M.; Ahmad, S.Prog. Org. Coat. 2004,50, 224-230.

9. Sharmin, E.; Ashraf, S. M.; Ahmad, S.Eur. J. Lipid. Sci. Technol. 2007, 109, 134-146.

10. Siyanbola, T. O.; Sasidhar, K.; Rao, B. V. S.
K.; Narayan, R. Olaofe, O.; Akintayo, E. T.; Raju, K. V. S. N. J. Am. Oil Chem. Soc.2015, 92, 267-275.

11. Dutta A.C. Botany for Degree Students, 5th edition, Oxford: Oxford University Press, (1964).

12. Ibiyemi S.A. Thevetia Plant Economic Potential: Chemistry's Key Position, 84 ${ }^{\text {th }}$ Inaugural Lecture of University of Ilorin, Kwara State Nigeria.(2007)

13. Güner, F. S.; Usta, S. Erciyes, A.T.; Yagci, Y.J. Coat. Techno.2000, 72, 107-110.

14. Siyanbola, T.O.; Sasidhar, K.; Narayan, R.; Anjaneyulu, B.; Rao, B.V.S.K.; Olaofe, O.; Akintayo, E.T.; Raju, K.V.S. N. International Research Journal of Pure and Applied Chemistry2015,8, 58-72.

15. Linday ME Practical introduction to microbiology. E and F.N. Spon, London, 177, (1962).

16. Cocks, L.V.; Rede, V. C.Laboratory handbook for oil and fat analyst. American Press, London and New York. (1966). 
17. Chattopadhyay, D. K.; Raju, K. V. S. N. Structuralengineering of polyurethane coatings forhigh performance applications.
Prog. Polymer. Sci.2007, 32, 352-418.

18. Janvi, I.; Petrovic, Z. S.; Guo, A.; Fuller, R.J Appl Polym Sci.2000,77, 1723. 